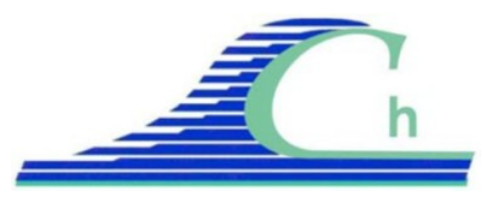

XII ${ }^{\text {ìmes }}$ Journées Nationales Génie Côtier - Génie Civil

Cherbourg, 12-14 juin 2012

DOI:10.5150/jngcgc.2012.063-D @ Editions Paralia CFL

disponible en ligne - http://www.paralia.fr - available online

\title{
Observation multiparamètres automatique par navire d'opportunités le long du continuum terre-mer de la rade de Brest et de la mer d'Iroise
}

\author{
Eric DUVIEILBOURG ${ }^{1}$, Georges CHAPALAIN ${ }^{2}$, Nicolas GUILLOU ${ }^{2}$
}

1. Laboratoire des sciences de l'Environnement MARin (LEMAR), Institut Universitaire Européen de la Mer (IUEM), Place Nicolas Copernic, Technopôle Brest-Iroise, 29280 Plouzané, France.

Eric.duvieilbourg@univ-brest.fr

2. Centre d'Etudes Techniques Maritimes Et Fluviales (CETMEF),

Laboratoire de Génie Côtier et Environnement (LGCE), 155 rue Pierre Bouguer, Technopôle Brest-Iroise, BP5, 29280 Plouzané, France.

Georges.Chapalain@developpement-durable.gouv.fr ;

Nicolas.Guillou@developpement-durable.gouv.fr

\section{Résumé :}

La présente note expose les aspects techniques, la mise en oeuvre, les premiers résultats et l'ébauche d'une application pour valider un modèle numérique du dispositif de surveillance automatique des paramètres hydrologiques (température, salinité, $\mathrm{pH}$, Chorophylle $a$, turbidité) des eaux de surface en mer d'Iroise et rade de Brest sur la ligne maritime régulière Brest-Molène-Ouessant.

A ce stade, les résultats montrent le potentiel de ces mesures pour mieux décrire, comprendre et prédire les processus-clés contrôlant les échanges le long du continuum terre-mer et assister les scientifiques, ingénieurs et gestionnaires impliqués dans le domaine de la qualité des eaux côtières.

\section{Mots-clés :}

Observation automatique - Navire d'opportunités - Hydrologie - Zone côtière Apports fluviatiles - Marée - Rade de Brest - Mer d'Iroise

\section{Communication non présentée}


Thème 3 - Instrumentation, mesures, imagerie et télédétection 
XII ${ }^{\text {èmes }}$ Journées Nationales Génie Côtier - Génie Civil

Cherbourg, 12-14 juin 2012 
Thème 3 - Instrumentation, mesures, imagerie et télédétection 
XII ${ }^{\text {èmes }}$ Journées Nationales Génie Côtier - Génie Civil

Cherbourg, 12-14 juin 2012 
Thème 3 - Instrumentation, mesures, imagerie et télédétection 
XII ${ }^{\text {èmes }}$ Journées Nationales Génie Côtier - Génie Civil

Cherbourg, 12-14 juin 2012 
Thème 3 - Instrumentation, mesures, imagerie et télédétection 